\title{
DA ANÁLISE ESTRUTURAL DA NARRATIVA (1996) À NARRATOLOGIA, DE WOLF SCHMID (2014). UM BREVE HISTÓRICO (TAMBÉM DA TERRA BRASILIS)
}

\author{
Gunter Karl Pressler ${ }^{1}$
}

\begin{abstract}
RESUMO
O ano de 1966 marcou a viagem dos Estruturalistas Franceses (R. Barthes, J.Lacan, G.Genette, J.P.Vernant, L.Goldmann, T.Todorov, N. Ruwet e J. Derrida) para o colóquio intitulado, As Linguagens da Crítica e as Ciências do Homem, organizado pela Universidade John Hopkins em Baltimore/EUA. Naquele ano também saiu o famoso número 8 da revista Communications ("Análise Estrutural da Narrativa") com os artigos iniciais da nova vertente teórica. Roland Barthes perspectivou, juntamente com outros estudos daquela revista, o do Todorov ("As Categorias da Narrativa Literária") e o de Genette ("Fronteiras da Narrativa"), a chamada ciência da narrativa. A partir do termo apresentado por Todorov (1982 [1969]: 10), surgiu "a narratologia, a ciência da narrativa". Nas décadas seguidas, a Narratologia incentivou centenas de pesquisas e projetos, por exemplo, o Centro Interdisciplinar para a Narratologia, na Universidade de Hamburgo (ICN) que já trouxe no curriculum um longo desdobramento sobre romances e narrativas na teoria alemã, anglo-saxônica e russa. A Narratologia é a primeira vertente da teoria literária que entrou no campo da reflexão da História, das Ciências Sociais e Políticas, da Comunicação, entre outros, pelo termo storytelling (Ch. Salmon, 2007). O nosso artigo desenha e narra o desenvolvimento histórico e o aprofundamento teórico sobre o discurso narrativo, o modo de narrar e as narrativas.
\end{abstract}

Palavras-chave: Narratologia. Estruturalismo. Barthes. Schmid.

\begin{abstract}
In the year 1966 the French structuralists (R.Barthes, J.Lacan, G.Genette, J.-P.Vernant, L.Goldmann, T.Todorov, N.Ruwet and J.Derrida) travelled to the United States to participate on the John Hopkins University in Baltimore an event named The languages of criticism and the sciences of man. In the same year was published the number 8 of Communications with the issue, "L'Analyse Structurale du Recit" which content articles by the new theorical wave. Roland Barthes aimed, together with other studies of the scientific journal, like Todorov ("The Categiries of literary Narrative") and Genette (Narratives Frontiers"), the so-called science of narrative. Over the decade, Narratology has encouraged hundreds of researches and projects, for exempla, the Interdisciplinary Center for Narratology at the University of Hamburg (ICN), which has already brought a long running outline of novels and narratives in German, Anglo-Saxon and Russian Narratological Studies. Narratology is the first strand of literary theory that has entered the field of the reflection of History, Social and Political Sciences, Communication, among others, by the term storytelling (Ch.Salmon, 2007). Our article draws and narrates the historical development and the theorical deeping on the narrative discourse, the way of narrating and the narratives.
\end{abstract}

Keywords: Narratology. Structuralism. Barthes. Schmid.

Recebido em: 10/08/2017

Aprovado em: 04/09/2017

\footnotetext{
${ }^{1}$ Professor de Teoria Literária na Universidade Federal do Pará/UFPA. Programa de Pós-Graduação em Letras (PPGL), Programa de Pós-Graduação em Linguagens e Saberes da Amazônia (PPLSA). E-mail: gupre@ufpa.br.
} 
A narrativa vence o conceito. Michel Serres

Gostaria de entrar no assunto com uma observação muito geral, aquilo que todo o mundo sabe, mas que ficaria uma "verdade reconhecida" na ciência somente se um grande nome expressasse esta verdade. "Inumeráveis são as narrativas do mundo. Há em primeiro lugar uma variedade prodigiosa de gêneros, distribuídos entre substâncias diferentes, como se toda matéria fosse boa para que o homem lhe confiasse suas narrativas" (Barthes, 2008 [1966], p. 19). "Uma tal universalidade da narrativa" - continua Roland Barthes com uma interrogação: “deve levar a concluir por sua insignificância?” Para um cientista, isto é um desafio: "Para descrever e classificar a infinidade das narrativas, é necessário pois uma teoria" (2008, p. 19 e 22). As questões de Barthes, antes de oferecer soluções, indicam o caminho de teoria (mais adiante já vem a resposta de T.Todorov) indutiva ou dedutiva? Quais são os critérios desta seleção e delimitação?

O "estruturalismo nascente", diz R.Barthes, naquele momento de 1966 - o "Ano-luz" para Françoise Dosse: “Tudo se desacreditou” (1994 [1991], p. 353; Vol.II) - colocou suas questões no interior da relação história e língua. As referências são Ferdinand de Saussure, os formalistas russos, Vladimir Propp e Claude Lévi-Strauss: “ou bem a narrativa é uma simples acumulação de acontecimentos, caso em que só se pode falar dela referindo-se à arte, ao talento ou ao gênio do narrador (do autor) ou então possui em comum com outras narrativas uma estrutura acessível à análise". ${ }^{2}$

A argumentação de Barthes desemboca numa solução no interior do Estruturalismo, porque "há um abismo entre a mais complexa aleatória e a mais simples combinatória, e ninguém pode combinar (produzir) uma narrativa, sem se referir a um sistema implícito de unidades e de regras" (2008, p. 21; grifo por mim). Metodologicamente, Barthes escolha o procedimento dedutivo (o indutivo desembocaria na morte de Funes, o memorial ${ }^{3}$ ): "Para descrever e classificar a infinidade das narrativas é necessário, pois, uma 'teoria' (no sentido

\footnotetext{
2 Barthes, 2008, p. 20; grifo por mim. Wolf Schmid conceitua esta situação como mediacy, Mittelbarkeit [mediação/mediador] (Schmid, 2010, p. 1).

${ }^{3}$ Lembramos ao conto de Luis Borges, "Funes, o Memorioso" (1944). "De fato, Funes não apenas recordava cada folha de cada árvore de cada monte, mas também cada uma das vezes que a havia percebido ou imaginado [...] Resolveu reduzir cada uma de suas jornadas pretéritas a umas setenta mil lembranças, que definiria logo por cifras [...] Nos deixam vislumbrar ou inferir o vertiginoso mundo de Funes. Este não o esqueçamos, era quase incapaz de idéias gerais, platônicas Era o solitário e lúcido espectador de um mundo multiforme, instantâneo e quase intolerantemente preciso. Havia aprendido sem esforço o inglês, o francês, o português, o latim. Suspeito, contudo, que não era muito capaz de pensar. Pensar é esquecer diferenças, é generalizar, abstrair. No mundo abarrotado de Funes não havia senão detalhes, quase imediatos" (Borges, 1975, p. 11 -117); cf. o artigo de Eliana Pereira (2012) e Júlio Pimentel Pinto (2001). Lembro-me do meu projeto de doutorado sobre a recepção de Walter Benjamin, em que queria relatar e analisar cada artigo, estudo, cada articulação sobre Benjamin. Tinha um orientador que me parou logo.
} 
pragmático do qual se acabou de falar) [...] No estado atual da pesquisa, parece razoável dar como modelo fundador à análise estrutural da narrativa à própria lingüística" (2008, p. 22; Barthes mesmo colocou o termo teoria entre aspas; grifo por mim).

Em poucos anos, Roland Barthes abandonou, como ressalta François Dosse (1994, p. 51), as ambições expressas no número da revista Communications, de 1966. O que aconteceu? Julia Kristeva, recém-chegada a Paris, frequenta os seminários de Barthes e traz na bagagem o nome de Mikhail Bakhtin, "desconhecido até então na França, e de quem ela se fez a introdutora ao prefaciar para [a editora] Le Seuil seus textos traduzidos para o francês [1963, 1965, 1970]" (1994, p. 73). Bakthin introduz na abordagem estruturalista a dinâmica histórica, a saída do fechamento do texto, "ampliar a inteligibilidade dos textos literários" (1994, p. 73). Dosse chama isto de "reviravolta de Roland Barthes": "A chegada dessa jovem búlgara ao seu seminário vai fazer sucumbir as ambições cientistas que ele exprimira tanto nos Elementos de Semiologia [1965] quanto em Crítica e Verdade [1966]. É uma verdadeira relação de permuta que ele institui com seus estudantes" (DOSSE, 1994, p. 76).

Em 1970, Barthes publica seu novo estudo S/Z. Com essa obra ele "desconstrói sua própria grade conceitual para dar maior liberdade à sua intuição literária” (Dosse 1994, p. 76). Isto se realizou com seu famoso livro O Prazer da Leitura (1973). E, percebemos pela palavra "desconstrução", que François Dosse usa a influência de Jaques Derrida sobre Barthes. Ele iria- pensando na metáfora de Borges - para o caminho de Funes com sua proposta da "análise textual", posterior da "análise estrutural". Também, é a saída e a vantagem do cientista acadêmico se tornando ensaísta, pois para apresentar seu estudo, não precisa se submeter a um sistema teórico de intersubjetividade da reflexão no contexto da comprovação do juiz de valores (referências de autoridades, a lógica científica). Barthes foi não só um cientista, como também um escritor.

Dois textos de Barthes, ainda daquela fase estruturalista, são muito utilizados nos estudos sobre narrativas. Um ensaio do livro O Grau Zero da Escrita (1953, traduzido no Brasil em 2002!), “A Escrita do Romance”, e a análise de um conto de Edgar Allan Poe do livro Semiótica Narrativa e Textual (1973), organizado por Claude Chabrol, publicado pela editora Cultrix, São Paulo, em $1977^{4}$. O último texto já demonstra sua saída da análise estrutural para a análise textual. Quem conhece o texto sabe que se trata um pouco do que caracteriza o Funes, de Borges.

\footnotetext{
${ }^{4} \mathrm{O}$ texto foi incluído, posteriormente, n’A Aventura semiológica, trad. Mário Laranjeira. São Paulo: Martins Fontes 2001 [1985].
} 
O que era um ensaio de 41 páginas, o de Barthes, em 1966, perspectivou juntamente com outros estudos da revista, o de Todorov ("As Categorias da Narrativa Literária" e o de Genette ("Fronteiras da Narrativa") uma nova vertente teórica, a Narratologia, que incentivou dezenas de pesquisas e projetos, por exemplo, o Interdisciplinary Centre for Narratology (Centro Interdisciplinar para Narratologia), na Universidade de Hamburgo. Os resultados de quatro décadas estão no livro de Wolf Schmid (2014; edições anteriores em russo, alemão e inglês), possibilitando diferenciações e caminhos verticais de pesquisa e mais de 70 livros publicados pelo grupo até hoje (meados do ano de 2017). O histórico desta vertente, desde o início do século 20 (K.Friedemann, H.James, G.Lukács, V.Slovskij, P.Lubbock, E.M.Forster, V.Propp, N.Friedman, F.K.Stanzel, E.Lämmert), passando pelos Estruturalistas (R.Barthes, J.Greimas, U.Eco, G.Genette), desembocou em trabalhos de S.Chatman, M.Bal, J.Lotman, S.Rimmon-Kenan, G.Prince, C.Reis/A.C.Lopes, D.Herman, A. e V.Nünning, J.Pier, J.Ch.Meister, W.Schmid, M.Fludernik) sem um sinal de debate no Brasil.

Todas as fontes indicam a seguinte definição de Tzvetan Todorov como certidão de nascimento daquela teoria que R. Barthes evocou, a Narratologia. A definição do "Manual da Narratologie", publicado em 2009 e acessível como Living Handbook of Narratology, constata:

The French term narratologie was coined by Todorov (1969, p. 10), who argued for a shift in focus from the surface level of text-based narrative [...] to the general logical and structural properties of narrative as a univers de représentarions_[...] Todorov thus called for a new type of generalizing theory that could be applied to all domains of narrative, and in fact for a hypothetical "science that does not exist yet; let's call it NARRATOLOGY, or science of narrative" (MEISTER, 2009, p. 331)

O texto original de Todorov diz

Nosso esforço aqui será de chegarmos a uma teoria da narração de modo que possa ser aplicada a cada um destes domínios. Consequentemente, mais do que dos estudos literários, esta obra depende de uma ciência que ainda não existe, digamos a Narratologia, a ciência da narrativa. Entretanto, os resultados desta ciência não serão desprovidos de interesse para o conhecimento da literatura, uma vez que a narrativa constitui, frequentemente, seu centro (1982 [1969], p. 10).

Gérard Genette colocou logo, neste contexto, "as fronteiras da narrativa" em vigor e se tornou referência internacional da Narratologia com seus trabalhos posteriores (1972, 1983 e 1991): "Definir positivamente a narrativa é acreditar que a narrativa é evidente, que nada mais natural do que contar uma história" - compare com as palavras de Barthes - "É necessário

5 "Cet ouvrage releve d'une Science qui n'existe pas encore, disons la narratologie, la science du récit" (1969, 10). O trecho está no livro, A Gramática do Decameron, trad. bras. Leyla Perrone-Moisés, 1982, p. 10: "O livro observa uma ciência que ainda não existe, vamos chamá-lo narratologia, a ciência da narrativa". 
voltar mais uma vez ao estupor de Valéry diante de um enunciado como 'A Marquesa saiu às cinco horas"'. Genette (2008, p. 265) constata que

a literatura moderna viveu e ilustrou esse espanto fecundo [...] Esta questão falsamente ingênua: por que a narrativa? - poderia pelo menos incitar-nos a pesquisar, ou mais simplesmente a reconhecer os limites de certo modo negativos da narrativa, a considerar os principais jogos de oposições por meio dos quais a narrativa se define, se constitui em face das diversas formas da não-narrativa

O artigo em 1966 ainda terminou com muitos "talvez" sobre o que fazer com o romance na "idade da representação"; talvez a narrativa [...] seja já para nós, como a arte para Hegel, uma coisa do passado" (2008, p. 284). A ciência da narrativa tornou-se o futuro da reflexão teórica posterior ao Estruturalismo e saiu, pela primeira vez, de dentro da Teoria da Literatura para as outras áreas das ciências modernas. Hoje se fala de "Narratologias" (HERMAN, 1999).

Este ano de 1966 também marca a viagem dos Estruturalistas Franceses (Barthes, Lacan, Genette, Vernant, Goldmann, Todorov, Ruwet e Derrida) para o colóquio intitulado As Linguagens da Crítica e as Ciências do Homem, organizado pela Universidade John Hopkins em Baltimore e incentiva uma onda norte-americana do estruturalismo, ligado ao nome de Paul de Man ${ }^{6}$. Os anais do evento foram publicados em 1970 por Richard Macksey e Eugenio Donato $^{7}$.

O que aconteceu naquele momento histórico no Brasil? Massaud Moisés publica, em 1967, seu caderno de ensino da história e teoria literária, elaborado desde março de 1952 , quando iniciou sua atividade de docência ("Prefácio da $1^{a}$ ed.", escrito em 26 de agosto de 1965, da Criação Literária, que está hoje na $20^{\text {a }}$ ed. 2006, com pequenas modificações, mas é o mesmo "manual da sua atividade de docente" desde a primeira publicação, em 1958, como “balão de ensaio” (já a 21 a ed. em 2006 e várias reedições até 2015). Em 1975 e 1978, Moisés acrescentou no prefácio uma réplica às críticas recebidas. Podemos imaginar o que ele quer dizer com "a crítica militante" ao assinalar "que algumas de minhas [MM] generalizações não podiam ser aceitas porque 'sem referências', como se eu tivesse escamoteado os autores

\footnotetext{
${ }^{6}$ Paul de Man nasceu como Paul Adolph Michel Deman na Bélgica, mas realizou sua carreira acadêmica, depois do seu doutorado na Harvad University, nos Estados Unidos.

${ }^{7} \mathrm{O}$ título indica a translatação do estruturalismo: Translation of The structuralist controversy: The languages of criticism and the sciences of man, an edited transcript of the proceedings of an international symposium, held Oct. 18-21, 1966, in Baltimore under the auspices of the Humanities Center of Johns Hopkins University (O livro foi traduzido, em 1976, pela editora Cultrix: A Controvérsia Estruturalista: as Linguagens da Crítica e as Ciências do Homem). Macksay foi director do Centro das Humanidades que foi fundado pela Fundação Ford. Eugenio Donato trabalhou, entre 1964 e 66, como professor de francês em Baltimore. O evento As Linguagens da Crítica e as Ciências do Homem, no qual participou Paul de Man ao lado dos franceses. Derrida proferia sua conferência, "Structure, Sign, and Play in the Discourse of the Human Sciences" derrubou, se dizem, o templo do Estruturalismo.
} 
estrangeiros em que me houvesse abeberado". Moisés (1997, p. 13) combate a crítica: "Na verdade [...] a crítica não escondia que lhe custava admiti-las [as postulações] como sendo de um brasileiro, e de um brasileiro que a partir da própria experiência e das próprias reflexões pudesse chegar a inferências plausíveis, defensáveis e, quiçá, originais”

O livro didático foi muito clarificador, particularmente seus esquemas dos "ingredientes", como ele chamou os elementos narrativos numa linguagem ala cuisine française/bourgeoise: ação, personagens, tempo, espaço e linguagem. Mas as reedições devem chegar, finalmente, ao limite, seu limite epistemológico, pois usar a literatura crítica ultrapassada, que tem um valor bastante informativo e descritivo, não é mais considerável. O mesmo diria ao livro de Flávio Kothe, A Narrativa Trivial (1994). No prefácio, o autor caracteriza seu livro como ensaio e se preocupa com o discurso ideológico e não "narratológico". Um livro até interessante para professores da comunicação, pois se desdobra sobre a "literatura de massa". Mas na Teoria da Comunicação já tem um "narratólogo", Luiz Gonzaga Motta que publicou, em 2013, Análise Crítica da Narrativa. A explanação do tema começa, como é o costume, desde o início remoto de todas as coisas e em termos gerais. A explanação que simplifica o assunto no tom de fala e não na linguagem científica ${ }^{8}$. O que quero dizer com isto? Tem mais falácia do que rigor de investigação científica. Em vez de estudar a literatura crítica, publicada desde o "ano-luz" de 1966, depois com Todorov, Motta se volta para aquele tempo que inventou ainda a roda da teoria literária (Aristóteles e companhia).

No capítulo 3, intitulado "A teoria da narrativa - Narratologia", Motta inicia com a seguinte frase: "O que é narrar? Narrar é relatar eventos de interesse humano enunciados em um suceder temporal encaminhado a um desfecho". Eu digo: "narrar" não é "relatar"! Sabe-se desde a graduação que se classifica vários gêneros ou tipos textuais, mas três modos de "enunciação": narrar, descrever e dissertar. O dicionário diz (o dicionário se ocupa com as palavras e não com as teorias): “v.t. Narrar, expor: relatar o ocorrido. Apresentar relatório". Para um cientista, o Dicionário é uma fonte de informação, não a autoridade em definir o assunto em questão e nem uma referência para analisar textos.

A explicação do dicionário indica como o verbo "relatar" uma relação com a realidade: Resumir, verbalmente ou por escrito, o conteúdo de um processo, de um projeto de lei etc., e sobre ele manifestar-se, para orientar a votação de seus pares em órgão de

\footnotetext{
${ }^{8}$ Uma ressalva, o autor relata que iniciou este livro como apostila num curso de graduação e, posteriormente, resolveu publicá-lo como um "manual” que poderia ser útil para alunos da pós-graduação; já falamos isto no caso do livro de Massaud Moisés, o que ocorreu há 50 anos; alguma coisa deve mudar, diria eu.
} 
deliberação coletiva. Quer dizer, com esta explicação estamos obviamente fora de textos ficcionais (literários) e no modo dissertativo. E não no modo narrativo! Estamos no campo de textos pragmáticos!

O que significa, na definição do dicionário, "evento"? O que quer dizer "de interesse humano"? Quem toma a decisão e com quais critérios? À proposição principal seguem duas sentenças secundárias numa construção de particípios passados: "enunciados" e "encaminhado". O infinitivo, por exemplo, pode ter função de substantivo; o gerúndio pode desempenhar função de advérbio ou adjetivo, enquanto o particípio pode valer por um adjetivo. O particípio é a forma nominal que expressa o resultado do fato verbal, ou seja, indica uma ação já realizada, finalizada. Focalizando mais, diria eu, significa investigar as implicações deste discurso do autor: trata-se de um discurso do imperativo categórico.

Pensando na forma do discurso do autor, o que quer dizer a "definição" de "narrar"? Temos a importância de tempo (duração, frequência), mas o desfecho? Quer dizer, desfecho intencional, estrutural e/ou casual?

Outro exemplo de se aproveitar de novas reflexões sobre narrativas, narração e Metahistória é o artigo de Alexandre Abreu. Ele apresenta sob o título "Narratologia e MetaHistoriografia" uma análise do romance A Gloriosa Família, de Carlos M. Pestana de Santos, aplicando suas leituras teóricas de forma mecânica. "O romance” - diz Abreu (2010, p. 29).

\footnotetext{
pode ser entendido como sofisticado recurso narratológico e metahistoriográfico. Ao dar voz para um mestiço mudo, tem-se uma profunda sistematização conceitual em narratologia, revigorando o papel do narrador em obras ficcionais. No romance percebemos a metahistória, que entende o estudo da história em uma multiplicidade de pontos de vista. Diante dessa perspectiva multifacetada, o valor documental de um texto narrativo literário se unifica ao valor do documento histórico e ajuda, até, a questionar o mesmo.
}

O autor sobre a metodologia, então, introduz: "a narratologia destaca-se como uma ferramenta pertinente de leitura e interpretação de obras ficcionais e não-ficcionais. Muito mais do que uma atribuição de nomenclaturas, a narratologia empreende uma tarefa de sistematização conceitual, revigorando estratégias de se abordar obras literárias” (2010, p. 29). E, logo depois, já está com seu latim no fim: Refere-se a T.Todorov (A Gramática do Decamaron, de 1982) e esclarece com Carlos Reis (esquecendo a mulher e coautora: Ana Cristina M.Lopez). Depois vai para V.Propp e A.J.Greimas, naturalmente, R.Barthes e G.Genette - tudo en passant -... (um tipo de Funes).

Onde Barthes começa ("Inumeráveis são as narrativas do mundo"), Motta e Abreu terminam ("Narrar é relatar eventos de interesse humano enunciados em um suceder temporal encaminhado a um desfecho"; "a narratologia empreende uma tarefa de sistematização 
conceitual"). Como ressaltamos, não se trata, nos texto referidos, de uma linguagem científica ou uma abordagem científica que deve ser comprovadamente entendida como uma linguagem lógica. Parecem mais narrativas do que textos críticos. Luiz Motta "se filia à narratologia", mas a Narratologia não é um clube, é uma teoria praticada e não recontada; deve prevalecer o modo dissertativo. A abordagem que toma a palavra Narratologia à moda, confirma o que já foi dito anteriormente, mas com outra terminologia - assim os termos de Gérard Genette (1978 [1972]), "narrador hetero-, homo e autodiegético", substituem os antigos termos "narrador onisciente/onipresente" e "Eu-narrador". Os trabalhos fundamentais de Genette, “Discours du Récit”, no livro Figuras III (1972), traduzido em Portugal (1978), e Nouveau Discourse du Récit (1983), não foram traduzidos no Brasil. A única fonte destes termos do pensamento de Genette, em português, é o livro traduzido sob orientação de Maria Alzira Seixo, em 1978, e o Dicionário de Teoria da Narrativa (1988, na editora Ática; saiu em Portugal, em 1987), de Carlos Reis ${ }^{9}$ e Ana Cristina M.Lopes.

A grande lacuna de estudos narratológicos stricto sensu, no Brasil, diante da velocidade e produtividade dos estudos no exterior desde a década de 1970 (Genette, 1972, 1983, 1991; Schmid, 1973, 2003 (russo), 2005, 2008, 2014 (alemão, edições sempre atualizadas e ampliadas), 2010 (inglês); S.Rimmon-Kenan, 1976; M.Bal, 1977, 1985; S.Chatman, 1978; D.Cohn, 1978, 1995; G.Prince, 1982, 1987; S.Lanser, 1986, 1987). A produção se triplicou na década de 1990.

Reconhecemos, então, abordagens sem conhecimento da literatura crítica. Não se trata de uma definição ou de um discurso científico, ao contrário, trata-se daquilo que se chama "falácia" no modo narrativo, provar eficazmente o que alega, sem argumentar, só convencer de modo implícito. Cada vez mais os termos da Narratologia entram no discurso, Alexandre Luiz Motta (2005, p. 215). diz:

a forma de narrativa de contar as coisas está impregnada pela narratividade, a qualidade de descrever algo enunciando uma sucessão de estados de transformação [...] que produz significações e dá sentido às coisas e aos nossos atos [...] o impulso cultural [consiste em] não apenas de narrar, mas de dar aos eventos um aspecto de narratividade

O que significa "narratividade" nesta construção frasal e redundante: a forma de narrativa "está impregnada pela narratividade"? O que são “eventos” que indicam "estados de

\footnotetext{
${ }^{9}$ Cf. a entrevista que C.Reis cedeu à revista Terra Roxa (Londrina/Paraná), em 2004, em que usa unicamente a terminologia de Genette. Reis é um dos organizadores do evento "International Conference Figures of Fiction", em que são tratados temas na perspectiva narratológica. O próximo evento ocorre em novembro deste ano, na Universidade de Coimbra.
} 
transformação", “dá sentido". Que sentido? ${ }^{10}$. O desdobramento sobre a literatura crítica e o acompanhamento do debate desde a década de 1970 está ausente. De repente, os novos autores se aproveitam dos resultados e aplicam mecanicamente e sem nexo lógico à terminologia.

Wolfgang Iser questiona a forma tradicional ou "universalista" do ato da interpretação literária e crítica. O estudioso parte da observação de W.K.Wimsatt e M.C.Beardsley sobre o que eles chamam a "affective fallacy", termo que indica o desaparecimento da obra diante da "confusão entre a obra (the poem) e seus resultados (what is and what it does - the poem)". Iser aproveita-se dos termos "intencional or affective fallacy"11 de Wimsatt e Beardsley para frisar os atos de leitura como atos de constituição da recepção de uma obra literária. As leituras não só de textos literários, afirma Iser, particularmente, as leituras da crítica executam "atos de determinação que definem o que é preferencial [...] Daí se deduz uma qualidade peculiar do texto literário". O horizonte da crítica pré-formada dificilmente capta "textos literários fora de tais atos de determinação". Se isso acontece, a crítica "tende a confundir a qualidade de suas determinações com a natureza do texto" (Iser, 1996, p. 61). Captar literatura “fora de tais atos de determinação" é muito difícil.

[Os textos] parecem figuras flutuantes que levam forçosamente o intérprete a fixálos em determinações. Se isso sucede, o crítico tende a confundir a qualidade de suas determinações com a natureza do texto, embora esta consista em induzir o crítico a realizar esses atos de determinação sem que esses atos se confundam com os resultados produzidos (ISER, 1996, p. 61).

O que vale para as leituras de textos literários vale para a dos textos teóricos. Eles são lidos de forma afetiva, i.e., já se compreende o que o texto quer dizer sem um desdobramento crítico sobre o debate em que o texto surgiu. Neste caso, a Narratologia não se compreende sem o histórico do seu aparecimento e desenvolvimento.

\footnotetext{
${ }^{10}$ Wolf Schmid elabora há mais de uma década uma terminologia que se adequa aos fenômenos pesquisados: "Duas concepções distintas da narratividade podem ser identificadas no estudo da literatura. A primeira se configurou na teoria clássica da narrativa, particularmente nos trabalhos dos críticos alemães, muito antes do termo narratologia ter sido introduzido [...] A existência da instância mediadora entre o autor e o mundo narrado foi a característica específica e definidora da narratividade na teoria clássica da narrativa [...] O segundo conceito da narratividade foi desenvolvido na Narratologia estruturalista, a partir de Tzvetan Todorov (1969). Nesta concepção, constitutivo para a narração não é um aspecto do discurso ou da comunicação, mas sim um aspecto próprio do que é narrado" (2014, p. 1-2; ver a conceituação detalhada no capítulo inteiro: "Narratividade", "Eventualidade" e "Ficcionalidade").

${ }^{11}$ Em português, "fallacy", poder ser traduzido por "falácia", "trapaça", "engano"; algo que induz a erro; o contexto do debate de Wimsatt/Beardsley e Iser indica que se trata de uma crença em que o significado (nosso caso, dado pela crítica) é dado como o significado correto (i.e., a natureza da obra), e isso pode ser intencionalmente ou por afeção.
} 
Para finalizar o breve histórico sobre narrativas e a ciência da narrativa, sempre pensamos em termos de conhecimentos, do debate em busca de novos epistemes, o autor da epígrafe, Michel Serres (2015, p. 64,. 72-74, 105). insiste:

\begin{abstract}
Todos precisamos de uma narrativa para existir [...] Que gênero de narrativa? [...] Esse contínuo-descontínuo da boca à orelha, da emissão e da recepção, feedback e envolvimento do gemido e da escuta, do grito e da audição, alimentação recíproca interna engendrando a individuação, pela consciência do tempo. O re- das palavras francesas recít [narrativas ou relato], relater [relatar], raconter [contar], rapporter [fazer o relatório]... exprimem e repetem essa dobra
\end{abstract}

\title{
REFERÊNCIAS
}

ABREU, Alexandre Veloso de. Narratologia e Meta-Historiografia: Estratégias Convergentes no Romance A Gloriosa Família de Pepetela. SCRIPTA (Belo Horizonte), v. 14, n. 27 , p. $29-35,2^{\circ}$ sem. 2010.

BARTHES, Roland, in: Comunications no. 8/1966.

BORGES, Jorge Luis. Ficções. Trad. Teixeira Coelho Netto. São Paulo: Círculo do Livro, 1975, p. $112-117$.

COMUNICATIONS NO. 8/1966 (L'Analyse Structural du Recit). Análise Estrutural da Narrativa. Trad. brasileira por Maria Zélia Barbosa Pinto; Introdução:. Milton José Pinto. Petrópolis: Vozes 1971, $5^{\text {a }}$ ed. 2008 (Novas Perspectivas em Comunicação, 1).

DOSSE, François. História do Estruturalismo. Vol. 1. e 2. Trad. Álvaro Cabral São Paulo: Ensaio/UNICAMP 1993/4 [1991] (Movimento de Idéias/Idéias em Movimento).

HÜHN, PETER/PIER, JOHN/SCHÖNERT, Jörg (Orgs.). Handbook of Narratology. Berlin: De Gruyter (009).

ISER, Wolfgang. O Fictício e Imaginário. Perspectivas de uma Antropologia Literária. Trad. Johannes Kretschmer. Rio de Janeiro 1996 [1991].

KOTHE, Flávio. A Narrativa Trivial. Brasília: EDUnB 1994.

MOISÉS, Massaud. A Criação Literária. 20ª ed. São Paulo: Cultrix 2006 [1967].

MOTTA, Luiz Gonzaga. Análise Crítica da Narrativa. Brasília: EDUnB 2013.

A Análise Pragática da Narrativa Jornalística. Disponível em:< http://www.intercom.org.br/papers/nacionais/2005/resumos/R2419-1.pdf,>. Acesso em: 23 Jul. 2017.

PEREIRA, Eliana. Apreensão e significação em "Funes, o Memorioso", de Jorge Luís Borges, In: Estudos Semióticos (São Paulo) junho de 2012, p. 91-98. Disponível em: 〈www.fflch.usp.br/dl/semiotica/es $>$. Acesso em: 26 jul. 2017. 
PINTO, Júlio Pimentel. Borges, uma Poética da memória, in: Borges, no Brasil, Jorge Schwartz (Org.). São Paulo: EDUNESP; Imprensa Oficial do Estado 2001, p. 121- 132.

PRESSLER, Gunter Karl. A Narrativa sem Fronteiras Textuais. O Liberal (Belém), 31 de março de 2016 (Magazine, p. 2).

SALMON, Christian. Storytelling, la machine à fabriquer des Histoires et à Formater les esprits. Paris: La Découvert/Poche 2007.

SCHMID, Wolf et alii. The living handbook of narratology. Disponivel em: <http://hup.sub.uni-hamburg.de//hn/index.php/Main_Page>. Acesso em: 26 jul. 2017

SCHMID, Wolf. Narratology. An Introdution. Trad. Alexander Starritt. Berlin/New York: De Gruyter 2010.

Gruyter 2014 [2008].

Elemente der Narratologie [Elementos da Narratologia] $3^{a}$ ed. Berlin: De

SERRES, Michel. Narrativas do Humanismo. Trad. Caio Meira. Rio de Janeiro: Bertrand Brasil 2015 [2006].

TODOROV, Tzvetan. A Gramática do Decameron. Trad. Leyla Perrone-Moisés. São Paulo: Perspectiva 1982 [1969]. 